\title{
Hurler syndrome
}

INSERM

\section{Source}

INSERM. (1999). Orphanet: an online rare disease and orphan drug data base. Hurler syndrome. ORPHA:93473

Hurler syndrome is the most severe form of mucopolysaccharidosis type 1 (MPS1; see this term), a rare lysosomal storage disease, characterized by skeletal abnormalities, cognitive impairment, heart disease, respiratory problems, enlarged liver and spleen, characteristic facies and reduced life expectancy. 